\title{
Treasure Hunt: Ethical Egoism vs Individual Anarchism
}

\section{Immanuel Setia Wijaya}

English Department, Faculty of Languages and Literature, Petra Christian University, Siwalankerto 121 131, Surabaya 60236, INDONESIA

Email: ayajiwleunammi@gmail.com

\begin{abstract}
This creative project is a novel with an urban-fantasy as the setting and adventure fiction as the plot framework. This novel is depicting a team of a treasure hunters, Michael Harmanto and Lucius Ferdinan. The two of them are trying to find the lost treasures of Kahja, in which they will be asked and tested in their perseverance and ego. In this creative work, I use Egoism as my topic, and I chose on understanding how egoism if applied ethically, can be treated as a good thing as my theme. Through this, I can show the process and the struggle of people clashing and betraying each other in the name of the egoistic desire of reaching their own personal goal. This story, topic, and theme were inspired by how it would be contrasting to the Indonesian philosophy as a nation. The main viewpoints which are ethical egoism and egoistical anarchism will be depicted in the way the two main characters Michael and Lucius' attitudes, methods, and results.
\end{abstract}

Keywords: ethical egoism, egoistic anarchism, urban-fantasy, adventure

\section{INTRODUCTION}

My decision to write about individualism came to me from my personal experience. I had an epiphany after I re-read the Atlas Shrugged (Rand, 1957) for the fourth time this year. The novel talked about the condemnation of an individual's desire in the name of the good of the collective and how each person's personal goal should not be sacrificed for another's. I started to think about whether the message of the book, that men should live according to their own and only for each of their own interests will have merit in the scope of societal values in Indonesian society.

Ayn Rand, who rejects faith and religion as a way to acquire knowledge, promotes what is known now as objectivism, a result-oriented principle where man is governed solely by to achieve happiness through product achievement and reason (Rand, 1992). In her books such as The Fountainhead (Rand, 1943) and Atlas Shrugged, Ayn Rand held the stance of egoist objectivist. Leonard Peikoff, the spiritual successor of Ayn Rand's philosophy, further elaborates that only an individual can only know what it is that he/she truly wanted and the method to achieve it. Therefore, since it is impossible for anyone to truly understand one another, it is imperative that an individual focused only on each his/her own individual goals without minding others. This philosophy which is so prevalent in her books, particularly The Fountainhead and Atlas Shrugged, is the exact opposite of Indonesia's collectivist culture as a country. Dr. Wustari Mangundjaya, a lecturer at Universitas Indonesia says, "According to the previous findings by Hofstede, Indonesian people are Collectivist, which prioritizes group over an individual." (Mangundjaya, 2013). I would like to expose the culture of individualism to the eyes of Indonesian readers through my novel, helped by using a close enough genre to Atlas Shrugged, the Urban Fantasy.

Urban-Fantasy books are characterized by the juxtaposition of fantastical creatures, magic, and myth in realistic, generally modern settings (California State Library. (n.d.). The most recognized example is the Harry Potter series. It combines the magical properties of supernatural/magic and the things or technologies of present-day reality. Unlike science-fiction, Urban-Fantasy does not contain more advanced technology than the present. Urban-fantasy genre, which encompassed many well-known works such as Percy Jackson and the Olympians, The Twilight Series, and the 
much-beloved Harry Potter Series. Particularly in the last two, Twilight and Harry Potter have redefined what it means to be a literary work aimed at young adults through its economic and cultural success. On a large scale, Harry Potter blurred the lines of mainstream culture and literary culture by turning reading books into something cool and profitable for general public consumption. While Twilight, on the other hand, is responsible for changing the perspective of vampires in the young adult community. Previously the standard of a good vampire is a hideous looking man with capes and monstrous powers to be slain by the heroes, nowadays, vampires have become synonymous with otherworldly handsome, often tragic characters who only wanted to fall in love. This perception has been ingrained since the 1930s has been changed with a single series and spawned "Handsome" Vampire media such as Vampire Diaries, True Blood, etc. this potential to influence the shape of the future works for a specific genre is why Urban-fantasy is my chosen genre. This genre is the most fitting for me to write in because the problems in the text are addressing real life, but simultaneously depicting it in a way for the reader in order to be fun to read. All of the events may not happen in the manner that is depicted in the story but is plausible in real life under different circumstances. by separating just a bit from the hard reality first then confronting them with a real problem experienced in the real world, I want the readers to experience the same kind of "Slap of truth" that the main character also did use the first-person narrative.

As for why I chose a novel, psychologists David Comer Kidd and Emanuele Castano, at the New School for Social Research in New York, have proved that reading literary fiction enhances the ability to detect and understand other people's emotions, a crucial skill in navigating complex social relationships (Kidd \& Castano, 2013). I hoped in using the novel as my creative thesis, I could influence the readers' emotions and their mindset towards personal goals and the collective's benefit.

My novel aims to address the importance of practicing moderation and caution between acting in one's best interest and harming others in the name of furthering one's own interest. In this novel, the two main characters, Michael and Lucius will be adventuring in a remote island in search of gold and glory. They will be faced with many obstacles that will test their resolve and worthiness towards achieving the goal.

\section{STATEMENT OF THE PROBLEM}

Through this creative thesis, I would like to explore people's mindset in achieving goals and what method they employ to reach the goal based on their mindset. lastly, I also would like to explore the possible outcomes from those respective methods.

Therefore, In this novel, I would like to explore how far exactly will an individual do in order to reach his or her goal. In the context of the novel, the above questions then become:

1. What is the difference between Michael and Lucius in how they see their goal.

2. What are the methods that Michael and Lucius applied to reach their goal.

3. What are the outcomes from Michael and Lucius respective methods.

\section{PURPOSE OF THE CREATIVE WORK}

The purpose of this creative work is to show that people can have different mindset even though aiming for the same goal. For example, one is an egoist and one is not even though the goal is the same. From the different mindsets, some may use honest methods while others may use dishonest methods. Lastly, the possible outcomes can be bad or good, depending on the methods employed. In the context of the novel, I would reveal:

1. Michael sees their goal as something that can be shared with others while Lucius sees their goal as something that should belong only to himself. 
2. Michael willingly cooperates and trusts in others' help to achieve their goal, while Lucius betrays everyone he worked with.

3. Michael ends up with a new partner and the glory of the treasure founder, while Lucius' name is stained forever.

\section{SIGNIFICANCE OF THE CREATIVE WORK}

My aim in creating this story is to show that Individualism might have a place in the collectivist society without erasing the collective identity. Individualistic tendencies might lead to a better, healthier society by achieving the balance of egoism and collectivism in the form of ethical egoism. Choosing to lean too much on the side of the majority of "common good" will result in the society that sacrificed an individual's life and achievement in order to fuel the common interest Consequently, leaning towards the egoism scale too much is not a feasible option for a man. Michael Tomasello, co-director of Max Planck Institute for Evolutionary Anthropology maintained that "humans like primates, have the tendency to cooperate... in search of validation and acknowledgment from other beings that are similar in stature," (Tomasello M. 2014). Therefore I aim for the readers to strive towards achieving the goal and balancing personal interests with the majorities.

Rand and Leikoff, the main figures of objectivism and consequently, individualism may be maintained that it is impossible for an individual to truly know what the others truly needs, and therefore we should not bother. Likewise, this meant for them that it is not enough that an individual must succeed in achieving this goal, other competitors must also fail. While achieving personal goals is important, it does not always have to be a competition or full of intrigue or betrayal. Even if egoism demands that a person only thinks about their own respective goals, it does not always mean that other people must not reach their goals in order for someone to succeed. This will be exemplified in my creative thesis, where Michael, one of the main characters will attempt to achieve his goals while fulfilling other people's goals as well, will be facing the other main character Lucius, who attempt to achieve his personal goals at any cost, even if he has to sacrifice others in the process.

Lastly, I would also attempt to make the readers understand the difference between pure selfishness and individualism. Selfishness is defined as behaving for immediate gratification and not caring about the consequences, while individualism demands that one only behaves in such a way that brings benefit to the individual, even if it is not direct or immediate. Understanding the difference can hopefully motivate the reader to step back and examine all the options before making a decision that will neither benefit many in spite of one nor benefit one at the expense of many, instead, it can benefit both.

\section{THEORY AND METHODOLOGY}

In this section, I would like to explain the theory that I used in making this creative work. The theory of Individualism aims to direct the protagonist's actions and decisions. I would also talk about the research that I do to obtain information that helps me to build the story as a whole.

\section{Theory}

In making this work, I chose individualism as the main theme of the story. Individualism in the very rough sense of the word means that one's self must always be the first priority over others. Individualism is really a big blanket term for many philosophies that govern self-importance, consisting of many ideas such as Objectivism, Individual Anarchism, Liberalism, Ethical Egoism. However, for the scope of this novel, only two will be explored deeper: Ethical Egoism and Egoistic Anarchism. 


\section{Ethical Egoism}

Ethical Egoism claims that each person has but one ultimate aim: to achieve a balance between the principle of egoism and the principle of equal consideration. (Kalin, J. 1975). Kalin describes that the ideal form of ethical egoism is the middle point between egoism: a person ought, all things considered, to do an action if and only if that action is in his overall self-interest, and the principle of equal consideration, where a person ought, all things considered, to do an action if and only if that action is in the general interest (where each person's welfare and interests are coordinated with every other person's welfare and interests.). This so-called balance means that while one can and must think of their personal objectives, one must also think about other's objectives and aims to fulfill those objectives even if it may delay one's endeavor as long the end result is still achieved.

Ethical Egoism in this creative work will be represented in the behavior and mindset of the first main character, Michael Harmanto. Using the principle of ethical egoism, Michael will behave in such a way that it fulfills his goal, but also to fulfill others' goal as well that are aligned with his.

Michael will start as a pure individualist that only thinks about achieving his goal of finding the treasure, but after a certain point in the story where this philosophy brings him disaster, his mindset will turn into the mindset of ethical egoism. He will find new allies in the form of Rosi that also want to find the treasure to achieve her goals to get out of the island. At the climax of the novel, where once again Michael will be forced to choose between getting the treasure for himself by sacrificing his new allies or keeping his word to share the treasure together, Michael will adhere to the ethical egoism principle and help others to get the treasure together instead of by himself.

Although in the theory itself, there was no exact guarantee that the outcome of ethical egoism will always result in a beneficial outcome for the philosophy, I would like to provide an example where such mindset is rewarded, just like what I had hoped if this behavior is applied in real-life situations.

\section{Egoistic Anarchism}

Individual Anarchism or Egoist Anarchism, on the other hand, is the end of the egoism spectrum. Max Stirner, the precursor of the modern egoism philosophy, held the view that "the only limitation on the rights of the individual is one's power to obtain what they desire." he also had this particular view that anything can be taken,"... Whoever knows how to take, to defend, the thing, to him belongs the property." (Stirner, M. 1844)

Individual Anarchism can be found in the other main character's behavior and mindset: Lucius'. While at first Lucius and Michael will start on the same end of the spectrum, as the story progressed, Lucius will slowly become more and more egotistical to the point of betraying his original partner Michael to get his hands on the goal, the Kahja treasure. The core of Individual Anarchism will become more apparent in the way Lucius will be engaging in senseless violence and unnecessary betrayals just to make sure that he himself will be getting the treasure. In the climax of the novel, Lucius will also be faced with a final chance to renounce this philosophy just like Michael. He will fail and will be faced with the logical consequences of all his cruel actions on the island. This theory, unlike ethical egoism, has an actual end result warning in the form of old dictators such as Nero and Hitler, who ended up dying after people get fed up with their inhumane actions. as such, I aim to portray the logical end result of such behavior in a negative way, as an attempt to dissuade the readers from adopting this philosophy. 


\section{METHODOLOGY}

For this work, I used secondary research as my idea and writing materials. I read some journals, data, and graphs on the internet that contained primary research done and related to ethical egoism and individual anarchism. Online journals such as the Canadian Journal of Philosophy, a paper by a lecturer in Universitas Indonesia, graphs regarding the rise of Individualistic tendencies in the future generations in the New York Times newspaper were some of the sources that I have read.

\section{Modes of Expression}

The genre I chose as a basis for my work is the Urban-Fantasy which is a subgenre of Fantasy. At the beginning of this novel, Michael is a naive young adult who has just arrived on the island with minimal preparations. As for the plot I have chosen to employ the standard plot of the adventure genre as the "vehicle" of the story. Urban fantasy is a subgenre of fantasy in which the narrative has magical rules or elements operating in an urban setting. Works of urban fantasy may be set in the real world and introduce aspects of fantasy, or in a fantasy world with operating rules recognizably similar to ours, complete with the good, the bad, and all the complex details which make it indistinguishable from the real world if not for the magical elements.

This main character will experience the difficulty of real-world interactions in the form of negotiations and bargains which will include many things, such as hypocrisy, lies, prejudice, and egoism. after facing through some of the hardships and failing, he will learn that in order to achieve the goal of finding the treasure sometimes a compromise has to be made, the personal goal must be shared and/or sacrificed. the opposite of this is the antagonist Lucius who blindly refuses to cooperate with anyone and only thinks about his own personal goal. he ended up failing to retrieve the treasure and meets a tragic end.

The works that inspire me for the writing style are The Dresden Files series (Butcher, 2000) and The Codex Alera series (Butcher 2004). I chose his style of writing of the first-person narrative because it opens up a new field of writing. In one of his books, Jim Butcher uses the first-person narrative in order to help the readers' immersion of the story and to empathize with the character. The main character is not observant so the readers will miss something while the other characters noticed in the series, but the readers did not until a character in-universe pointed out to him and consequently to the readers as well. He also managed to craft a sense of hostility and suspicion just like in real life when the main character is confronted by people gossiping even though they had nothing to do with the plot, simply because of his own prejudice and unfortunate timing, which is a natural response for a person in real life.

In the Introduction to the Encyclopedia of Adventure Fiction, Critic Don D'Ammassa defines the genre as follows, "-An adventure is an event or series of events that happens outside the course of the protagonist's ordinary life, usually accompanied by danger, often by physical action. Adventure stories almost always move quickly, and the pace of the plot is at least as important as characterization, setting and other elements of creative work."

What makes my creative work different than another contemporary fantasy is that my work uses two different viewpoints: on the first one-third of the novel, it will be using third-person omniscient narrative, then the last two-thirds will be a first-person perspective from the two main characters. While there are novels that did the opposite, which was the first-person view first then the third person: The Lovely Bones (Sebold, 2002), or novels that mix them up like Dragonfly in Amber (Gabaldon, 1992), my book does The reason for this is that at the beginning I want the reader to see what they look like from the perspective of a bystander, and then after a certain point of the story when the two protagonists split up the perspective changes to the first person in order 
to let the reader know what is actually going in the mind of each main character and shed some light to their respective behavior in the first one-third of the novel.

My direction of this novel is different in that at the end of the novel, the main character Michael, who will accept that he cannot find the treasure by himself and agreed to share some of the glory with others is the one that ended up finding it in the end. He understands that while thinking of a personal goal is essential, one must not forget that honest cooperation on achieving a single goal will always triumph over people who cheat and betrays others in order to achieve their goal. The outline of the creative work will be like this chapter 1: main protagonist's introduction, 2: supporting character and antagonist introduction, a step forward in the treasure hunt, 3: another step forward in the treasure hunt, the turning point that divided the boys, 4: the final leg of the treasure hunt shown in first-person point-of-view of the two boys, 5: the climax of the confrontation and epilogue. all the chapters will be shown in third-person perspective except chapter 4 which will be in first-person, alternating between Michael and Lucius.

The reason I chose a fictional island as the setting, is because I want to avoid resemblance to any actual locations, practices, or even cuisines in any part of the world. I chose to make it ambiguous in order to invite the reader's imagination to add in their own experience to the story to make it even more "realistic". My aim is to let the readers insert themselves and immerse themselves in the story to make it even more engaging.

\begin{tabular}{|c|c|c|}
\hline Story Elements & $\begin{array}{l}\text { Conventions of Urban } \\
\text { Fantasy }\end{array}$ & $\begin{array}{l}\text { Conventions of my } \\
\text { Creative Work }\end{array}$ \\
\hline Setting & $\begin{array}{l}\text { Set in the primary, } \\
\text { "real" world, or a rational and } \\
\text { familiar fictional world, with } \\
\text { the inclusion of magical } \\
\text { elements in an integrated. }\end{array}$ & $\begin{array}{l}\qquad \text { My work is set in the } \\
\text { fictional Sinato Island, more } \\
\text { specifically, a remote fictional } \\
\text { island located somewhere } \\
\text { within the minor islands of } \\
\text { Bali, at the end of the 20th } \\
\text { century, with the inclusion of } \\
\text { minor supernatural elements. }\end{array}$ \\
\hline Theme & \begin{tabular}{l}
\multicolumn{1}{c}{ Has a thematic } \\
concern with the Unseen. This \\
Unseen is largely related to a \\
social Other that portrays \\
unpleasant aspects of urban \\
life, such as criminality, \\
homelessness, addiction, \\
prostitution, and physical and \\
sexual abuse.
\end{tabular} & $\begin{array}{l}\qquad \text { My story centers } \\
\text { around the pursuit of a goal, } \\
\text { and what lengths the character } \\
\text { will go to in order to fulfill it. } \\
\text { Betrayal, murder, coercion, } \\
\text { blackmail are some of the } \\
\text { aspects that will appear in the } \\
\text { story. }\end{array}$ \\
\hline Fantasy Elements & $\begin{array}{l}\text { The complete } \\
\text { juxtaposition of the fantastic } \\
\text { and urbanity or modernity in a } \\
\text { primary-world setting or in a } \\
\text { setting that emphasizes notions } \\
\text { of the urban and modern in a } \\
\text { secondary world. }\end{array}$ & $\begin{array}{l}\text { The low appearance of } \\
\text { traditional fantasy elements } \\
\text { within the story-there is just } \\
\text { enough fantasy elements to } \\
\text { make the line between reality } \\
\text { and fantasy blurred, creating a } \\
\text { sense of ambiguity. Magic } \\
\text { exists in the world but only in } \\
\text { the scope of the island and the }\end{array}$ \\
\hline
\end{tabular}




\begin{tabular}{|c|l|l|}
\hline Character & $\begin{array}{l}\text { Characters are } \\
\text { marginalized by society. Only } \\
\text { one character or a few have } \\
\text { magical abilities. }\end{array}$ & $\begin{array}{l}\text { Michael and Lucius } \\
\text { treasure. the chanding the } \\
\text { explain it, it just works. }\end{array}$ \\
\hline $\begin{array}{l}\text { are both Foreigners that have } \\
\text { no allies on the island before } \\
\text { the story began. They have no } \\
\text { deep understanding of the } \\
\text { culture, legend or geography } \\
\text { of the island. }\end{array}$ \\
\hline
\end{tabular}

\section{Theme}

This work deals with human nature, egoism. Most of the time, people will say egoism is a bad thing. However, I would like to propose a contrasting view. Egoism applied in an ethical context can be treated as a good thing. In order to try to elaborate more on my point of view, I have decided to make the theme of my work as "The world will be a better place if everyone is acting in accordance with their own personal interests together". In my story, Michael and Lucius will be faced with various obstacles such as the island locals, magical flora and fauna, personality trials. in the end, Michael who shared goals and joined with others succeed while Lucius who keep only thinking about himself and persevering alone failed.

\section{Conflicts}

The conflicts in this novel are man vs man: more specifically in the latter two-thirds of the novel, where Lucius and Michael have split up and trying to get into the treasure location. Michael and Lucius will be clashing in philosophies regarding whether is it worth to get lone glory at the cost of others? in chapter 4 onward, however, the conflict briefly morphs into a man vs himself when the boys are contemplating the event that divides them, the betrayal of Lucius.

\section{CONCLUSION}

As a final thought, I hope that my creative work had managed to answer the questions I put forth in the clearest possible way. In pursuit of the treasures of Kahja, the two main protagonists Lucius and Michael ended up as enemies caused by the difference in attitudes towards achieving the goal. Lucius who employed the egoistic anarchism mindset, ended up employing the brutal method by betraying everyone he worked with in the form of letting Michael die in the hand of Jakob, poisoning Jakob's crew, purposefully navigating harder terrain in climbing the mountain, and in the end, attempting to trap Michael on an avalanche one last time after he saved his life in the climax, ended up with no treasure, no crew, and his name are forever ruined in when the news about what he's done gets around. Michael, on the other hand, employs ethical egoism, also ended up not getting the treasure but he gained other things that are not related to the treasure. Through his kindness and willingness to share profits and glory with other people allows him to come out on top. His willingness to trust and help Rosinan and other villagers ended up saving his life on the climax when they managed to clear the debris to save him just in time. While I can not guarantee this outcome will happen if this philosophy is applied in the real world, I would like to believe that just like in my creative work, ethical egoism will be rewarded instead of egoistic anarchism.

Throughout the process of making the creative work, I gathered a lengthy list of theories about egoism that I never knew existed before. I obtained a new understanding regarding egoism and 
what exactly caused it and how it is depicted in various cultures. On the subject of actually writing the work, I now had much more appreciation about action scenes in general. I have not written a violent action scene in my previous works before this creative work. Trying to decide whether a scene can be condensed in narration, or even whether it should be condensed at all is also the first time in my attempt in writing. I am grateful to my advisor's advice to keep me continue writing since normally I would attempt to correct the things I had just wrote and ended up not moving and deleting all of the progress. This is my first time not to do that in an academical setting to learn to just, write "subpar" in my standard. I would like to edit my story still in the future. I considered this a rush job that I hoped to edit to achieve my ideal standard of a story. I would attempt to make a series using the same settings and maybe the same character. Maybe a prequel with the parents just to elaborate on how exactly they got to this point. If there are people that would like to explore the egoism theory in the future, I would like to raise the point of view of the background of egoism. Tying egoism into a specific culture such as capitalism or communism maybe. Since my work only reflects on two types of egoism, and there are still much more type of egoism out there in society.

\section{REFERENCES}

D'Ammassa, D. Encyclopedia of Adventure Fiction. Facts on File Library of World Literature, Infobase Publishing, 2009 (pp. vii-viii).

Ekman, S. (2016)Urban Fantasy: A Literature of the Unseen

Mangundjaya, W. L. H. (2013). Is there cultural change in the national cultures of Indonesia? In Y. Kashima, E. S. Kashima, \& R. Beatson (Eds.), Steering the cultural dynamics: Selected papers from the 2010 Congress of the International Association for CrossCultural Psychology.

Kalin, J. (1975). Two Kinds of Moral Reasoning: Ethical Egoism as a Moral Theory. Canadian Journal of Philosophy, 5(3), 323-356.

Kidd, D., \& Castano, E. (2019). Reading Literary Fiction and Theory of Mind: Three Preregistered Replications and Extensions of Kidd and Castano (2013). Social Psychological and Personality Science, 10(4), 522-531.

Rand, A. (1992) [1957]. Atlas Shrugged (35th anniversary ed.). New York: Dutton.

Rand, A (1943) The Fountainhead

Stirner, Max. The Ego and Its Own, p. 248

Tomasello M. (2014). The ultra-social animal. European journal of social psychology, 44(3), 187-194. 